\title{
Nanoceramics from the Ball Mill
}

\author{
Chemists at the Max Planck Institute for Coal Research in Germany have found a way to \\ produce corundum, a particularly stable variant of alumina, in the form of nanoparticles \\ using simple mechanochemistry in a ball mill. The particles could be used, among other \\ things, as a resistant carrier material in automotive catalysts or as a starting material for \\ particularly hard ceramics. A first industrial company is already working on the large-scale \\ production of nanocorundum.
}

In its most precious variants, corundum forms rubies and sapphires because of traces of chromium, iron, or titanium. However, material scientists are not that interested in it as a gemstone. Because it can almost compete with diamond in terms of hardness and is also extremely resistant to heat and chemicals, corundum is used in catalysis and for ceramic implants in dentistry, prostheses, and for cutting tools. Ceramics could be made even more break-resistant if they were produced from nanoparticles of corundum. Such a manufacturing process would also require less

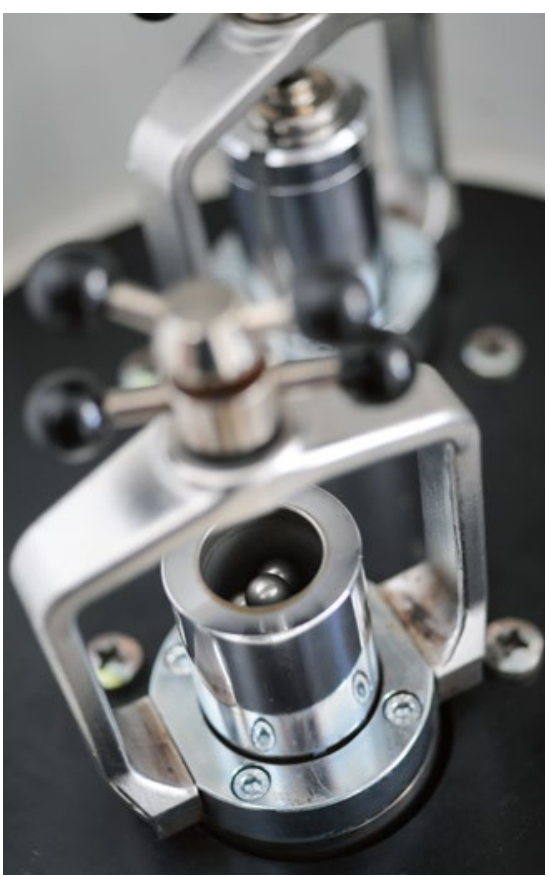

Figure 1 A simple chemical process: Boehmite, aluminium oxyhydroxide, is ground for about $3 \mathrm{~h}$ to produce corundum nanoparticles with a surface area of $140 \mathrm{~m}^{2} / \mathrm{g}$. (๑) Frank Vinken/ MPI für Kohlenforschung) energy. Nanoparticles of corundum could also simplify the construction of automotive catalysts, the catalytically active components of which would then become more stable. Up to now, the automotive industry has been using a less stable form of alumina in a complex process.

Corundum in nanoparticulate form is highly interesting for the chemical industry. "There are reports that catalysts with a carrier material made of corundum work more efficiently for the production of ammonia," says Ferdi Schüth, Director at the Max Planck Institute for Coal Research. "In other catalytic processes, such as the production of synthetic fuels, the higher stability could be essential." Nanoparticles in form of corundum may therefore find numerous applications in the future because now they are easily accessible through the simple mechanochemical process found.

The researchers can obtain a powder of the corundum nanoparticles by simply grinding lumps of boehmite, aluminum oxyhydroxide contained in the frequently occurring ore bauxite, in a ball mill for $3 \mathrm{~h}$ and then heating them briefly. Until now, chemists were only able to produce corundum from other aluminum oxides or hydroxides if they fired the starting materials at temperatures greater than $1200{ }^{\circ} \mathrm{C}$ or pressurized them at milder temperatures of $500{ }^{\circ} \mathrm{C}$ for weeks. However, especially after high temperature treatment, instead of nanoparticles larger crystals were formed.

"We discovered by chance that nanoparticles of corundum are produced in a ball mill," says Ferdi Schüth. His team investigated whether a catalytic reaction in such a mill works better because the catalyst is always given a fresh surface where the reactants can meet. They used a soft alumina (gamma-alumina) mixed with gold particles as a catalyst and followed the process in the ball mill with various analytical methods. It was revealed that after only a few hours, part of the gamma-alumina had been converted into corundum. However, the corundum obtained had moderate nanocrystallinity. "But this raised our expectations and we then systematically tested several variants of alumina and aluminum (oxide)hydroxides as starting materials. Eventually, we identified boehmite as a particularly interesting precursor due to its structural water," says Amol Amrute, one of the leading scientists in this project.

Chemists are now able to explain why a process as trivial as grinding opens up a route to a mineral that can otherwise only be obtained under harsh conditions and certainly not in nanoparticulate form. The shocks that the precursor boehmite experiences in the mill provide exactly the mechanical energy that is necessary for the rather complex conversion of the boehmite structure to corundum.

The researchers, who specialize in the development of new catalysts, are now investigating how nanocorundum is used as a catalyst material in various reactions such as the production of synthetic fuels. Potential customers have already expressed interest, and a process is currently being developed to produce large quantities of the nanoparticulate corundum.

Contact:

Max Planck Institute for Coal Research, Mülheim an der Ruhr, Germany, www.kofo.mpg.de/en 